Journal of

Food and Nutrition

\title{
Evaluation of The Efficacy of a Dietary Supplement in Alleviating Symptoms in Dogs with Osteoarthritis
}

\author{
Elisa Martello ${ }^{1, *}$, Mauro Bigliati ${ }^{2}$, Raffaella Adami ${ }^{3}$, Elena Biasibetti ${ }^{1}$, Franco Dosio ${ }^{4}$, Daniela Pastorino ${ }^{5}$, Na- \\ tascia Bruni ${ }^{3}$
}

${ }^{1}$ Dipartimento di Scienze Veterinarie, Universita’ degli studi di Torino, Grugliasco (TO), Italy

${ }^{2}$ Ambulatorio Vernazza, Torino, Italy

${ }^{3}$ Candioli Pharma S.p.A., Beinasco (TO), Italy

${ }^{4}$ Dipartimento di Scienza e Tecnologia del Farmaco, Universita' degli studi di Torino, Torino, Italy

${ }^{5}$ Clinica veterinaria Monferrato, Alessandria, Italy

*Corresponding author: Elisa Martello, Dipartimento di Scienze Veterinarie, Universita degli studi di Torino, Largo P. Braccini 2, 10095 Grugliasco (TO), Italy; Tel: +447510999441; E-mail: martello.elisa@gmail.com

Received Date: November 24, 2018; Accepted Date: December 26, 2018; Published Date: December 29, 2018

Citation: Elisa Martello (2018) Evaluation of The Efficacy of a Dietary Supplement in Alleviating Symptoms in Dogs with Osteoarthritis. J Food Nutr 4: 1-8.

\begin{abstract}
In this study, we investigated the anti-inflammatory and pain relief effects of a new canine diet supplement containing a mixture of Boswellia serrata Roxb., Curcuma longa, green tea extract, glucosamine, chondroitin sulfate, hyaluronic acid, and collagen type II-not hydrolised in dogs with osteoarthritis. A total of 13 dogs with osteoarthritis were enrolled in the study. All of them were orally administered with the diet supplement for 60 days. All the animals were subject to veterinary evaluations and owners filled questionnaires on chronic pain (Helsinki chronic pain index). All the patients completed the study, no side effects and no changes in the basic metabolism was reported, confirming the safety and tolerability of the product. Combining results from the veterinarian and from the owner evaluations, most of the dogs improved their condition. The treatment resulted more effective in severe cases. Several treatment options are currently available for treating dogs with osteoarthritis, but there is an increasing interest in the use of diet supplements given their efficacy and safety. Our findings suggest that our dietary supplement has beneficial effects in alleviating chronic orthopedic pain and in reducing clinical signs in dogs with osteoarthritis.
\end{abstract}

Keywords: Osteoarthritis; Boswellia; Lameness; Chronic pain; Dietary supplement

\section{Highlights}

Osteoarthritis is a common cause of chronic pain in dogs.

Diet supplements are valid alternative to alleviate chronic pain.

Diet supplements are safe and have anti-inflammatory and pain relief effects.

C 2018 The Authors. Published by the JScholar under the terms of the Creative Commons Attribution License http://creativecommons.org/licenses/by/3.0/, which loize.marechal@umontreal.ca

maximilien.laviolette-brassard@umontreal.ca 


\section{Introduction}

Osteoarthritis (OA), also known as degenerative joint disease, is a condition common in both humans and companion animals that has been described for over a hundred years [1]. As in humans, the pathogenesis of canine OA involves changes in all tissues of the synovial joint. OA happens when trauma or cellular damage changes the normal homeostasis of the joint, releasing inflammatory mediators and degradative enzymes. Chronic pain and disability are the result of the deterioration of the articular cartilage. The most frequent causes of disease in dogs are the excessive exercise, trauma and/or genetic predisposition. In dogs aging more than 1 year, OA is very common. In addition, breed, gender, animal size and weight are common risk factors. The course of OA is very slow; common findings are the degeneration of the cartilage, hypertrophy of bone at the margins and changes in the synovial membrane [2].

Diagnosing OA in dogs begins with owners observing the pain and stiffness. The owners usually notice the pain while the animal is doing its common activities during the day. Pain is a very subjective sensation, therefore, it is very difficult to assess. In human medicine, the patient provides information on its condition, in case of dogs, other methods must be adopted. In the past years, several questionnaires have been developed and validated to assess acute and chronic pain in animals [3-5]. In particular, the owner has been found to be able to identify signs of chronic pain and to highlight changes of attitude and behavior of affected dogs over time. For example, the Helsinki chronic pain index (HCPI) has been validated for chronic pain associated with OA in dogs through the use of a multifactorial and descriptive owner questionnaire. The HCPI consists of 11 questions on the dog's mood, lameness, and willingness to move, play, and jump [5-7].

A part from this, veterinary evaluations are valuable and objective tools to diagnose OA and to classify the level and progress of the disease when setting up a treatment. Radiographic evidence, patient symptoms, type and degree of lameness and OA risk factors can help predicting the risk of joint degradation [2].

Unfortunately, once clinically evident, OA cannot be cured in both animals and humans. Therefore, being pain the dominant symptom, the current goal of any treatment given is the management of the chronic pain and associated loss of function. In both humans and dogs, the most common approaches include lifestyle changes (i.e. weight loss, reduced exercise, etc.), surgical treatment, or the use of drugs (nonsteroidal anti-inflammatory drugs, NSAIDs; N-methyl-D-aspartate, NMDA, inhibitors; Opioids; Corticosteroids) $[1,8,9]$. These agents are of variable efficacy but may be associated with a significant number of side effects, toxicities, and tolerance over time [10]. Accordingly, there has been significant inquiries into different approaches to OA. Physiotherapy, acupuncture, and hydrotherapy are increasingly used as complimentary therapies [11]. The use of dietary supplements and traditional herbal medicinal products in dogs and other companion animals are becoming of great interest in the scientific veterinary community although there are limited numbers of rigorous randomized controlled trials currently available as pointed out by some researchers [12]. Beside this, these dietary supplements present the advantage of having few side effects but chondroprotective and anti-inflammatory properties as reported in in vivo studies $[7,13]$.

Glucosamine regulates the synthesis of collagen in cartilage and may provide mild anti-inflammatory effects, while chondroitin sulfate inhibits destructive enzymes in joint fluid and cartilage. The two work in a synergic manner [14] increasing their own positive effects on cartilage. They could also be found associated with other chondro protectants such as the hyaluronic acid or the undenatured type II collagen, being the latest able to reduce pain and improve joint mobility and flexibility [15-17]. In addition, natural ingredients like Boswellia serrata [13,18], Curcuma longa [18-20] and green tea extract $[19,21]$ orally administered singly or in combination, have been reported to be safe and to have beneficial effects in the treatment of inflammatory processes in animals and humans.

In this study, we investigated the anti-inflammatory and pain relief effects of a new canine diet supplement containing a mixture of Boswellia serrata Roxb., Curcuma longa and green tea extract in addition to some chondro protectants (Glucosamine (purity 99\%), chondroitin sulfate (low molecular weight, purity $100 \%)$, hyaluronic acid, collagen type II-not hydrolised) on client owned dogs with OA reporting chronic pain.

\section{Materials \& Methods}

\section{Animals included and recruitment}

Medium to large-breed client-owned dogs with OA were recruited from the Veterinary Clinic VETLAN (Battipaglia, Italy) between February and June, 2015. The dogs' owners were informed about the purpose and design of the study and they provided a written informed consent before the enrollment of their animal. All procedures, treatments and animal care were in compliance with the guidelines of the Italian Minister of Health for the care and use of animals (D.L. 4 March 2014 n. 26 and D.L. 27 January 1992 n.116). Inclusion criteria were: presence of clinical and radiographic signs of OA on at least one joint with no evidence of any other disease according to the clinical history, physical examination and blood test results. Exclusion criteria were: dogs with acute pain, signs of recent trauma or surgery on any joint in the past 6 months, neurological conditions, treatment with NSAIDs, corticosteroids or antimicrobials within 14 days before enrolment.

\section{Study design and the dietary supplement}

This study was designed as a prospective observational clinical study. Tablets of a dietary supplement produced by the Candioli Pharma S.p.A (Italy) containing mainly Boswellia serrata Roxb., Curcuma longa and green tea extract in addition to glucosamine (purity 99\%), chondroitin sulfate (low molecular weight, purity 100\%), hyaluronic acid, collagen type II-not hydrolised, were orally administered in dogs once daily for a total of 60 days. A full list of ingredients is reported in Table 1. The dose was calculated according to animals' weight. All dogs were subject to a veterinary evaluation and an owner evaluation at different time points during the observational period: baseline (T0), then after 30 (T1) and 60 (T2) days. All applicable 
international, national and/or institutional guidelines for the care and use of animals were followed.

\begin{tabular}{|l|c|}
\hline Ingredients & $\begin{array}{l}\text { Quantity in 2.0 gr of } \\
\text { tablet (mg) }\end{array}$ \\
\hline Hyaluronic acid & 18 \\
\hline Appetite stimulants (D'Tech 8P) & 134 \\
\hline Collagen type II-not hydrolised & 4 \\
\hline Chondroitin sulfate & 700 \\
\hline $\begin{array}{l}\text { FLEXIDE (Camellia sinensis (L.) O. } \\
\text { Kuntze, Boswellia serrata Roxb. ex } \\
\text { Colebr., Copper complexes of chlo- } \\
\text { rophylls E141) }\end{array}$ & \\
\hline \begin{tabular}{l} 
Glucosamine hydrochloride \\
\hline $\begin{array}{l}\text { Technological additives (antioxi- } \\
\text { dants, emulsifiers, stabilizing agents) }\end{array}$
\end{tabular} \\
\hline
\end{tabular}

Table 1. Ingredients included in the tested supplement. Quantity of each ingredient contained in 2.0 grams of tablet is reported.

\section{Veterinary Evaluation}

An orthopedic veterinary specialist performed the medical assessment of each dog at baseline, at 30 and at 60 days post-treatment. During the visits, clinical general examination, orthopedic examination, blood test (complete blood count and blood chemistries, at T0 and T2 only) were performed. A radiological assessment was carried out at the first visit to confirm the diagnosis, no significant changes in the radiographic findings are expected to be found after 60 days of treatment, indeed no other X-ray were performed at T1 and T2. Data on sex, age, breed, body weight, body condition score (BCS, 9 points scoring system), body temperature, examination of superficial lymph nodes, heart/pulse rate, respiratory character, and mucous membrane color were recorded. In addition, the specialist evaluated the animal pain progression grading the lameness at T0, T1 and T2 ( 1 to 4 scale, where 1 is for mild and 4 is for severe). Based on the classification of the type of lameness, the change in condition from T0 to T2 was also recorded. Indeed, the animals were classified at the end of the study as "successful" (no longer lame), "improved" (improvement from $\mathrm{T} 0$ to $\mathrm{T} 2$ with reduction of clinical signs and pain; i.e. from continuous to intermittent lameness), "failure" (unchanged clinical condition or worsened).

\section{Owner Evaluation}

Chronic pain was assessed with an Italian adapted version of the validated Helsinki Chronic Pain Index (HCPI), a functional behavior-based owner questionnaire for veterinarian use based on an article written by Canapp and colleagues [7] (Table 2). Questions translated from English into Italian might be slightly different due to wording and language variations, despite this the validity of the Index is not compromised. The questionnaire contains 11 questions on the dog's mood, lameness, and willingness to move, play, and jump. The questionnaire takes into account the emotional aspect of the pain. The index number was derived from the 5 possible answers (scores of $0-4$, scores of 0 and 1 indicate normal behavior and movement, scores of 2, 3 , and 4 indicate pain with increasing severity). Owners were asked to mark only the answer that best described their dog. There is a possible minimum index number of $0(11 \times 0)$ and a possible maximum index number of 44 (11 x 4). Therefore, healthy dogs usually have an HCPI between 0 and 11 , assuming that an individual score of 1 is considered normal. Dogs with chronic pain will have a score of 12-44. This index is one of the most commonly applied as an outcome measure in clinical trials where chronic pain is evaluated by owners [4-6].

\section{Statistical Analysis}

Mean dog weight (Kilograms, Kg), age (years, yr) and standard deviation (SD) were calculated. Fraction of males and females were reported. Median value of the starting point of the lameness expressed in months was calculated. Percentage of animals with different grades and type of lameness and the fraction of animals classified as improved, failure or successful were included in the results. Graphical representations (histograms) of the HCPI questionnaire outcomes were performed.

\section{Results}

All the 13 patients enrolled in the study completed the protocol. Dogs' ages ranged from 18 months to 10 years (mean $4.8 \pm 2.8 \mathrm{SD}$ ), with 4 dogs $(31 \%)$ being females and 9 dogs $(69 \%)$ being male. Breeds of dogs in the study were: German Shepherds (3), Setter (3), Siberian Husky (1), Dobermann (1), Pitbull terrier (2), Mixed Breed (2), one was not reported. They were all companion dogs. Body weights ranged from 15 to $36 \mathrm{~kg}$ (mean $27.7 \pm 8.1 \mathrm{SD} \mathrm{kg}$ ). The two eldest dogs had a BCS of $7 / 9$ and $8 / 9$. The other dogs had a BCS of $3 / 9$ ( 4 dogs) and 5/9 (6 dogs), one score was missing. The superficial lymph nodes, heart/pulse rate, respiratory character, the rectal body temperature and mucous membrane color were confirmed as normal in all animals during the three examinations. Differences in blood test results at the beginning and at the end of the study were negligible and closely linked to the individual animal pre-existing conditions, no significant changes in the renal and liver function was reported. The radiographic examination confirmed OA condition in all cases with one or more joints involved. More specifically, the joints affected by OA (number of cases) are listed here: knee (3 unilateral), knee and elbow ( 1 bilateral), hip ( 2 unilateral), tarsus ( 1 unilateral, 1 bilateral), carpus and shoulder (1 unilateral), carpus and elbow (1 unilateral), carpus ( 1 bilateral), elbow ( 1 unilateral, 1 bilateral).

No side effects of the supplement were reported; no episodes of diarrhea or vomiting was pointed out. Moreover, none of the owners had difficulties in the administration of the tablets.

The owners informed the veterinarian about the starting point of the lameness in their dogs, it ranged approximately between 2-24 months (median=6) before the enrollment in the study.

The specialist evaluated the animal lameness progression grading it at T0, T1 and T2 during the performed orthopedic examinations (Table 3 ). Specifically, four animals started with grade $2(4 / 13,31 \%)$, six animals with grade $3(6 / 13,46 \%)$, 


\begin{tabular}{|l|l|l|l|l|l|}
\hline Question asked & 0 Points & $\mathbf{1}$ Point & 2 Points & 3 Points & 4 Points \\
\hline $\begin{array}{l}\text { Q1 } \\
\text { Rate your dog's mood }\end{array}$ & Very alert & Alert & $\begin{array}{l}\text { Neither alert } \\
\text { nor indifferent }\end{array}$ & Indifferent & Very indifferent \\
\hline $\begin{array}{l}\text { Q2 } \\
\text { Rate your dog's willingness to partici- } \\
\text { pate in play }\end{array}$ & Very willing & Willing & Reluctantly & Very reluctantly & $\begin{array}{l}\text { Does not play } \\
\text { at all }\end{array}$ \\
\hline $\begin{array}{l}\text { Q3 } \\
\text { Rate your dog's vocalization (audible } \\
\text { complaining) }\end{array}$ & Never & Hardly ever & Sometimes & Often & Very often \\
\hline $\begin{array}{l}\text { Q4 } \\
\text { Rate your dog's willingness to walk }\end{array}$ & Very willing & Willing & Reluctantly & Very reluctantly & $\begin{array}{l}\text { Does not walk } \\
\text { at all }\end{array}$ \\
\hline $\begin{array}{l}\text { Q5 } \\
\text { Rate your dog's willingness to trot }\end{array}$ & Very willing & Willing & Reluctantly & Very reluctantly & $\begin{array}{l}\text { Does not trot } \\
\text { at all }\end{array}$ \\
\hline $\begin{array}{l}\text { Q6 } \\
\text { Rate your dog's willingness to gallop }\end{array}$ & Very willing & Willing & Reluctantly & Very reluctantly & $\begin{array}{l}\text { Does not gallop } \\
\text { at all }\end{array}$ \\
\hline $\begin{array}{l}\text { Q7 } \\
\text { Rate your dog's willingness to jump } \\
\text { (e.g., into car, onto sofa) }\end{array}$ & Very willing & Willing & Reluctantly & Very reluctantly & $\begin{array}{l}\text { Does not jump } \\
\text { at all }\end{array}$ \\
\hline $\begin{array}{l}\text { Q8 } \\
\text { Rate your dog's ease in lying down }\end{array}$ & With great ease & Easily & $\begin{array}{l}\text { Neither easily } \\
\text { nor difficultly }\end{array}$ & With difficulty & $\begin{array}{l}\text { With great dif- } \\
\text { ficulty }\end{array}$ \\
\hline $\begin{array}{l}\text { Q9 } \\
\text { Rate your dog's ease in rising from a } \\
\text { lying position }\end{array}$ & With great ease & Easily & $\begin{array}{l}\text { Neither easily } \\
\text { nor difficultly }\end{array}$ & With difficulty & $\begin{array}{l}\text { With great dif- } \\
\text { ficulty }\end{array}$ \\
\hline $\begin{array}{l}\text { Q10 } \\
\text { Rate your dog's ease of movement after } \\
\text { long rest }\end{array}$ & With great ease & Easily & $\begin{array}{l}\text { Neither easily } \\
\text { nor difficultly }\end{array}$ & With difficulty & $\begin{array}{l}\text { Very often/al- } \\
\text { ways difficulty }\end{array}$ \\
\hline $\begin{array}{l}\text { Q11 } \\
\text { Rate your dog's ease of movement after } \\
\text { majorivity or heavy exercise }\end{array}$ & With great ease & Easily & $\begin{array}{l}\text { Neither easily } \\
\text { nor difficultly }\end{array}$ & With difficulty & $\begin{array}{l}\text { Very often/al- } \\
\text { ways difficulty }\end{array}$ \\
\hline
\end{tabular}

Table 2. Helsinki Chronic Pain Index (HCPI) for veterinary use, as translated from Finnish to English based on an article written by Canapp and colleagues [7].

and three with grade $4(3 / 13,23 \%)$. In only two cases the grade of lameness remained the same, in the other cases an improvement was recorded as showed in Table 3.

In addition, the veterinarian evaluated the change in the type of lameness through the whole study period (Table 3). Most of the animals started with a continuous lameness at the first visit $(8 / 13,62 \%)$, while four with continuous cold lameness $(4 / 13,31 \%)$ and one with intermittent lameness $(1 / 13$, $8 \%)$. As regards the type of lameness, after the 60 days of treatment most of the animals meliorate their clinical condition $(9 / 13,69 \%)$, and four animals remained the same $(4 / 13,31 \%)$. Finally, the animals were classified at the end of the study based on the whole set of clinical examinations as "successful" $(1 / 13,8 \%)$, “improved" $(11 / 13,84 \%)$ or "failure" $(1 / 13,8 \%)$ (Table 3).

Questionnaires were completed by all the owners at T0, T1 and T2. Only two questionnaires, one at T0 and one at $\mathrm{T} 1$, had been excluded from part of the analysis since we had missing answers and the total Index couldn't be calculated. Based on the HCPI, in only three cases $(3 / 11,27 \%)$ we had a baseline Index slightly lower than 11, corresponding to the upper limit for considering a dog "healthy" based on the literature. The other Indexes varied from 11 to 33 (Figure 1). Dogs with a HCPI between 11 and 19 at T0 had a final score at T2 similar to the initial one, no significant differences can be highlighted (Figure 1). The three cases with the highest Index (HCPI >20), representing the set of animals with the maximum intensity of chronic pain in our study based on owners' evaluation, showed a final score reduced significantly after the 60 days of treatment (Figure 2). No age, weight, breed or sex effect was observed (data not shown) on the outcomes of interest but the study was not designed for this purpose and the number of cases were not enough to perform further statistical analysis.

\section{Discussion}

$\mathrm{OA}$ is frequently encountered in veterinary practice and is associated with important changes in animal behavior and activities. The main focus of the clinician is managing pain in affected animals and slowing down the progression of disease and improving exercise tolerance, mobility, and quality of life. Currently, several therapeutic options are available to 


\begin{tabular}{|c|c|c|c|c|c|c|c|}
\hline \multirow[t]{2}{*}{ Cases } & \multicolumn{3}{|c|}{ Degree of lameness } & \multicolumn{3}{|c|}{ Type of lameness } & \multirow{2}{*}{$\begin{array}{l}\text { Overall clas- } \\
\text { sification }\end{array}$} \\
\hline & T0 & T1 & T2 & T0 & T1 & T2 & \\
\hline Case 1 & 2 & 1 & 1 & $\begin{array}{l}\text { continuous } \\
\text { lameness }\end{array}$ & cold lameness & $\begin{array}{l}\text { Intermittent } \\
\text { lameness }\end{array}$ & Improved \\
\hline Case 2 & 3 & 3 & 2 & $\begin{array}{l}\text { continuous } \\
\text { lameness }\end{array}$ & $\begin{array}{l}\text { continuous } \\
\text { lameness }\end{array}$ & cold lameness & Improved \\
\hline Case 3 & 2 & 2 & 2 & $\begin{array}{l}\text { continuous } \\
\text { lameness }\end{array}$ & $\begin{array}{l}\text { continuous } \\
\text { cold lameness }\end{array}$ & $\begin{array}{l}\text { intermittent } \\
\text { cold lameness }\end{array}$ & Improved \\
\hline Case 4 & 2 & 1 & 2 & $\begin{array}{l}\text { continuous } \\
\text { lameness }\end{array}$ & cold lameness & cold lameness & Improved \\
\hline Case 5 & 3 & 1 & 1 & $\begin{array}{l}\text { continuous } \\
\text { cold lameness }\end{array}$ & no lameness & no lameness & Success \\
\hline Case 6 & 3 & 2 & 2 & $\begin{array}{l}\text { continuous } \\
\text { lameness }\end{array}$ & $\begin{array}{l}\text { continuous } \\
\text { cold lameness }\end{array}$ & $\begin{array}{l}\text { continuous } \\
\text { cold lameness }\end{array}$ & Improved \\
\hline Case 7 & 3 & 2 & 1 & $\begin{array}{l}\text { continuous } \\
\text { cold lameness }\end{array}$ & $\begin{array}{l}\text { continuous } \\
\text { cold lameness }\end{array}$ & $\begin{array}{l}\text { intermittent } \\
\text { lameness }\end{array}$ & Improved \\
\hline Case 8 & 3 & 2 & 2 & $\begin{array}{l}\text { continuous } \\
\text { lameness }\end{array}$ & $\begin{array}{l}\text { continuous } \\
\text { lameness }\end{array}$ & cold lameness & Improved \\
\hline Case 9 & 4 & 3 & NA & $\begin{array}{l}\text { continuous } \\
\text { cold lameness }\end{array}$ & $\begin{array}{l}\text { continuous } \\
\text { lameness }\end{array}$ & $\begin{array}{l}\text { intermittent } \\
\text { cold lameness }\end{array}$ & Improved \\
\hline Case 10 & 2 & 2 & 1 & $\begin{array}{l}\text { Intermittent } \\
\text { cold lameness }\end{array}$ & $\begin{array}{l}\text { Intermittent } \\
\text { cold lameness }\end{array}$ & $\begin{array}{l}\text { Intermittent } \\
\text { cold lameness }\end{array}$ & Improved \\
\hline Case 11 & 4 & 4 & 4 & $\begin{array}{l}\text { continuous } \\
\text { cold lameness }\end{array}$ & $\begin{array}{l}\text { continuous } \\
\text { lameness }\end{array}$ & $\begin{array}{l}\text { continuous } \\
\text { lameness }\end{array}$ & Failure \\
\hline Case 12 & 3 & 2 & 2 & $\begin{array}{l}\text { continuous } \\
\text { lameness }\end{array}$ & $\begin{array}{l}\text { continuous } \\
\text { lameness }\end{array}$ & $\begin{array}{l}\text { continuous } \\
\text { lameness }\end{array}$ & Improved \\
\hline Case 13 & 4 & 2 & 2 & $\begin{array}{l}\text { continuous } \\
\text { lameness }\end{array}$ & NA & cold lameness & Improved \\
\hline
\end{tabular}

Table 3. Patients' lameness progression. Degree of lameness at T0, T1 and T2. Type of lameness at T0, T1 and T2. Overall classification of the animal's condition after 60 days from the beginning of the treatment.

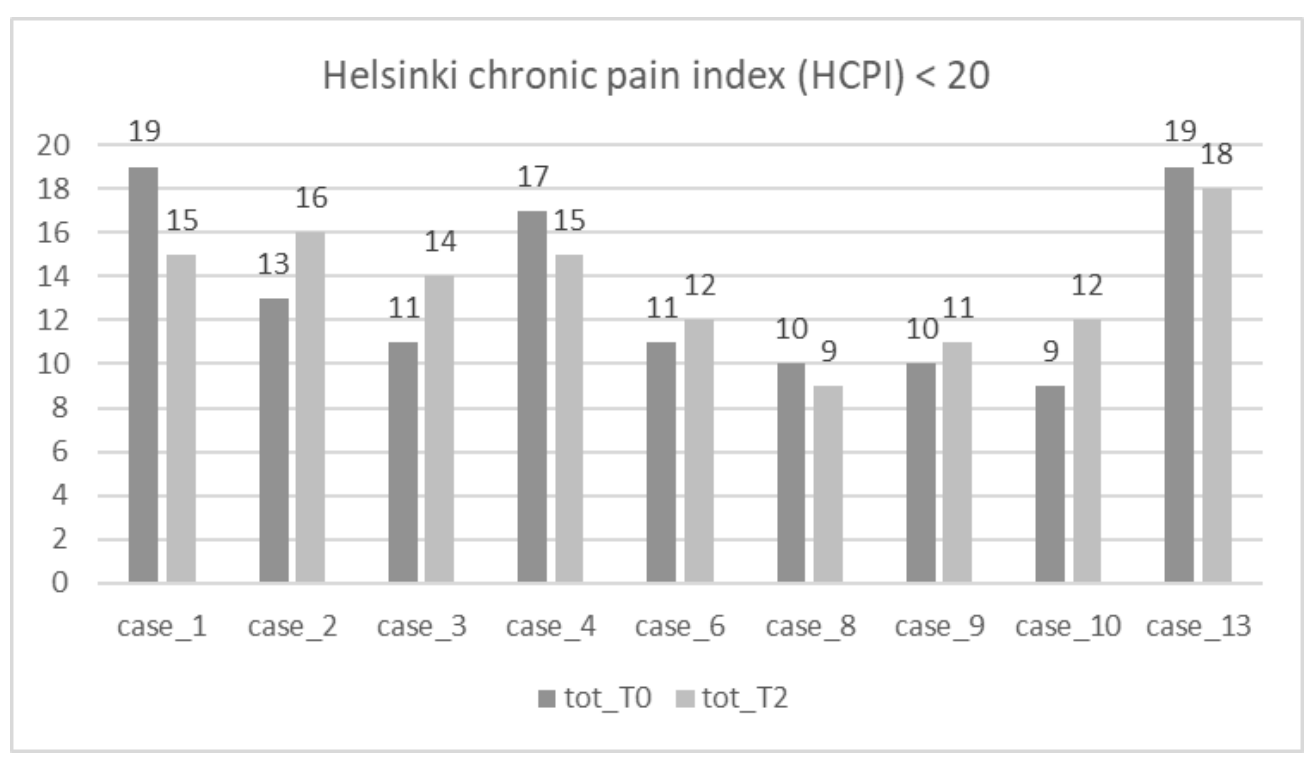

Figure 1. The Helsinki chronic pain index (HCPI) at T0 (tot_T0) and T2 (tot_T2) in 9 cases with baseline HCPI <20. On the top of each bar the HCPI is reported. 


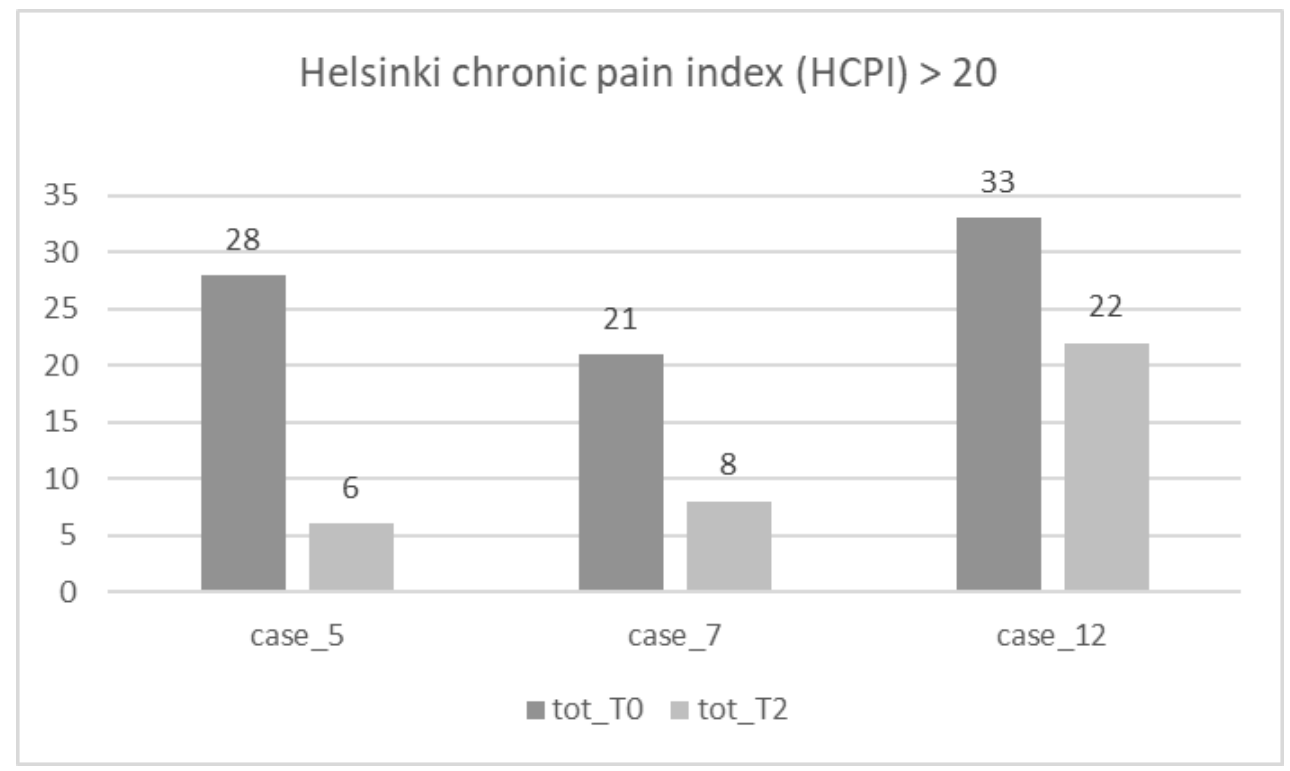

Figure 2. The Helsinki chronic pain index (HCPI) at T0 (tot_T0) and T2 (tot_T2) in the three cases with baseline HCPI $>20$. On the top of each bar the HCPI is reported.

the veterinarian and the use of oral supplements is becoming a popular option presenting the advantage of having few or no known side effects [22]. In agreement with the scientific literature, the supplement we administered in this study didn't have an influence on the metabolic condition of the patients being the general clinical conditions and blood test results very similar to the baseline and no other side effects were reported. This clearly confirms the safety and tolerability of the administered product in our patients. Being OA a chronic disease, long-term treatments with products with minor side-effects are preferred. The risk of side-effects associated with longterm administration of commonly used drugs like NSAIDs, has led to have increased interest in disease modifying agents such as diet supplements [8]. There is some evidence that a prolonged, regularly and conscientiously administered use of supplements ( 8 weeks or longer) is required to see significant improvements in patients [15]. Indeed, we planned a 60 days study period and at the end of the study, we were able to see good improvements in clinical signs and behavior. It is very common in the veterinary practice to see a beneficial effect of a treatment with either traditional drugs or supplements when the lameness and pain are severe. In fact, during our study we found three cases we classified as the most severe and both the veterinarian and the owner pointed out an evident positive outcome after the 60 days of treatment. In one case we even reported the actual success. In the other dogs (a part from one) an improvement of the clinical conditions was highlighted by the specialist only and this can be considered a very good result for the treatment of less severe cases. On the other hand, based on the HCPI, we cannot confirm that in these same cases the animal mood, lameness, and willingness to move, play, and jump based on the owner's opinion were ameliorated. The reason why this happened could be addressed to the less serious general condition of the dog and the smaller pain reported at the baseline compared to the most severe cases. Chronic pain is very difficult to assess, and even if psychometric properties of the questionnaire used are valid and reliable, the capability of the owner to see differences in their animal behavior in this conditions is minimal. Unfortunately, pain status for some dogs might change even from day to day, depending on weather, extra activity, and other events, making any interval between the two visits too long to get the score the closest to the reality [5]. Answering to the questionnaire could be quite subjective, and a difference of a few points could have varied our final HCPI. Finally, in these less severe cases we could consider the specialist final report the most reliable result of the treatment. In general, diet supplements have been reported to be well tolerated and absorbed quickly, but some authors pointed out that further studies are needed to add information concerning their bioavailability, the mechanism of action of some products is often speculative and their efficacy not always supported by rigorous scientific studies [22]. Despite this, using diet supplements and in particular, multicomponent formulations seems to be very common in the recent research and in practice, with the idea that several components together have an optimal effect [23]. Following this, the novelty of our diet supplement is the mixture of several ingredients each of them reported in literature to have relevant positive effects (used singly or in combination) on the treatment of different inflammations and in particular on OA in humans and animals. But, in none of these studies they were all combined together as it is in our formulation. For example, some studies have indicated that when administered together to dogs, glucosamine and chondroitin are absorbed in as little as two hours [16] and the action is even synergistic [24], moreover the addition of undenatured Type II Collagen was found even more effective in a placebo-controlled study conducted by D'Altilio and colleagues [17]. In another study performed with working dogs, similar effects were noticed in the group treated with a diet supplement (glucosamine, chondroitin sulphate, and hyaluronic acid) and in the one with Carprofen [15]. As regards natural curcumin we used in our supplement, a major concern in the literature is the absence of information concerning its bioavailability in dogs. In fact, 
it is known for its very low bioavailability as also reported in Comblain and colleagues [22]. But, the technology used for the formulation of both Boswellia serrata Roxb. and Curcuma longa as phytosomes in our supplement, was really patented in order to ensure the better intestinal absorption. In a study conducted by Reichling and colleagues [13], these two important ingredients were found to be effective in the treatment of dogs suffering from inflammatory joint and spinal disease. This is evidence in support of our choice of including also these two natural ingredients in our preparation. Finally, curcuminoids extract, in combination with hydrolyzed collagen and green tea extract, was also found to be effective in an in vitro study [21].

\section{Conclusion}

Our results indicated that the dietary supplement was beneficial in alleviating chronic orthopedic pain and in reducing the clinical signs in dogs with OA after 60 days of treatment. This study supports the concept that oral supplements with a combination of natural products can be effectively used in managing the natural OA process in dogs with no or negligible side effects. Based on the limited number of cases and the absence of a control group, further studies would be useful to consolidate our results.

\section{Acknowledgements}

We wish to thank the staff of the Veterinary Clinic VETLAN (Battipaglia, Italy) for the excellent work and for providing the cases. The study was supported by the Candioli S.p.A. (Italy).

\section{Conflict of interest}

Two of the authors are employees of the Candioli Pharma S.p.A. Two of the authors are scientific consultants for the Candioli Pharma S.p.A. Candioli Pharma S.p.A is a company that may be affected by the research reported.

\section{Reference}

1) Cimino Brown D (2017) What can we learn from osteoarthritis pain in companion animals? Clin Exp Rheumatol 35 Suppl 107: 53-58.

2) Bland S (2015) Canine osteoarthritis and treatments: a review. . Veterinary Science Development 5.

3) Reid JN, AM; Hughes, JML; Lascelles, D; Pawson, P; Scott, EM (2007) Development of the short-form Glasgow Composite Measure Pain Scale (CMPS-SF) and derivation of an analgesic intervention score. Animal Welfare 16 (S).

4) Molsa SH, Hielm-Bjorkman AK, Laitinen-Vapaavuori OM (2013) Use of an owner questionnaire to evaluate long-term surgical outcome and chronic pain after cranial cruciate ligament repair in dogs: 253 cases (2004-2006). J Am Vet Med Assoc 243: 689-695.

5) Hielm-Bjorkman AK, Rita H, Tulamo RM (2009) Psychometric testing of the Helsinki chronic pain index by completion of a questionnaire in Finnish by owners of dogs with chronic signs of pain caused by osteoarthritis. Am J Vet Res 70: 727-734.

6) Hielm-Bjorkman AK, Kuusela E, Liman A, Markkola A, Saarto E, et al. (2003) Evaluation of methods for assessment of pain associated with chronic osteoarthritis in dogs. J Am Vet Med Assoc 222: 1552-1558.

7) Canapp SO, Jr., Leasure CS, Cox C, Ibrahim V, Carr BJ (2016) Partial Cranial Cruciate Ligament Tears Treated with Stem Cell and Platelet-Rich Plasma Combination Therapy in 36 Dogs: A Retrospective Study. Front Vet Sci 3: 112.

8) Innes JF, Clayton J, Lascelles BD (2010) Review of the safety and efficacy of long-term NSAID use in the treatment of canine osteoarthritis. Vet Rec 166: 226-230.

9) Pettitt RA, German AJ (2015) Investigation and management of canine osteoarthritis. In Practice 37: 1.

10) Monteiro-Steagall BP, Steagall PV, Lascelles BD (2013) Systematic review of nonsteroidal anti-inflammatory drug-induced adverse effects in dogs. J Vet Intern Med 27: 1011-1019.

11) Silva N, Luna SPL, Joaquim JGF, Coutinho HD, Possebon FS (2017) Effect of acupuncture on pain and quality of life in canine neurological and musculoskeletal diseases. Can Vet J 58: 941-951.

12) Vandeweerd JM, Coisnon C, Clegg P, Cambier C, Pierson A, et al. (2012) Systematic review of efficacy of nutraceuticals to alleviate clinical signs of osteoarthritis. J Vet Intern Med 26: 448-456. 
13) Reichling J, Schmokel H, Fitzi J, Bucher S, Saller R (2004) Dietary support with Boswellia resin in canine inflammatory joint and spinal disease. Schweiz Arch Tierheilkd 146: 71-79.

14) Hochberg MC, Martel-Pelletier J, Monfort J, Moller I, Castillo JR, et al. (2016) Combined chondroitin sulfate and glucosamine for painful knee osteoarthritis: a multicentre, randomised, double-blind, non-inferiority trial versus celecoxib. Ann Rheum Dis 75: 37-44.

15) Alves JC, Santos AM, Jorge PI (2017) Effect of an Oral Joint Supplement When Compared to Carprofen in the Management of Hip Osteoarthritis in Working Dogs. Top Companion Anim Med 32: 126-129.

16) Beale BS (2004) Use of nutraceuticals and chondroprotectants in osteoarthritic dogs and cats. Vet Clin North Am Small Anim Pract 34: 271-289, viii.

17) D'Altilio M, Peal A, Alvey M, Simms C, Curtsinger A, et al. (2007) Therapeutic Efficacy and Safety of Undenatured Type II Collagen Singly or in Combination with Glucosamine and Chondroitin in Arthritic Dogs. Toxicol Mech Methods 17: 189-196.

18) Del Grossi Moura M, Lopes LC, Biavatti MW (2017) Oral herbal medicines marketed in Brazil for the treatment of osteoarthritis: A systematic review and meta-analysis. Phytotherapy Research 31: 1676-1685.

19) Comblain F, Barthelemy N, Lefebvre M, Schwartz C, Lesponne I, et al. (2017) A randomized, double-blind, prospective, placebo-controlled study of the efficacy of a diet supplemented with curcuminoids extract, hydrolyzed collagen and green tea extract in owner's dogs with osteoarthritis. BMC Vet Res 13: 395.

20) Henrotin Y, Priem F, Mobasheri A (2013) Curcumin: a new paradigm and therapeutic opportunity for the treatment of osteoarthritis: curcumin for osteoarthritis management. Springerplus 2: 56.

21) Comblain F, Sanchez C, Lesponne I, Balligand M, Serisier S, et al. (2015) Curcuminoids extract, hydrolyzed collagen and green tea extract synergically inhibit inflammatory and catabolic mediator's synthesis by normal bovine and osteoarthritic human chondrocytes in monolayer. PLoS One 10: $\mathrm{e} 0121654$.

22) Comblain F, Serisier S, Barthelemy N, Balligand M, Henrotin Y (2016) Review of dietary supplements for the management of osteoarthritis in dogs in studies from 2004 to 2014. J Vet Pharmacol Ther 39: 1-15.

23) Bolognesi G, Belcaro G, Feragalli B, Cornelli U, Cotellese R, et al. (2016) Movardol(R) (N-acetylglucosamine,
Boswellia serrata, ginger) supplementation in the management of knee osteoarthritis: preliminary results from a 6-month registry study. Eur Rev Med Pharmacol Sci 20: 5198-5204.

24) McCarthy G, O'Donovan J, Jones B, McAllister H, Seed M, et al. (2007) Randomised double-blind, positive-controlled trial to assess the efficacy of glucosamine/chondroitin sulfate for the treatment of dogs with osteoarthritis. Vet J 174: 54-61. 